\title{
OS IMPACTOS NA RENDA DAS FAMÍLIAS DA COMUNIDADE DE SOMBRAS GRANDES E MILAGRES: O CASO DO PROJETO DOM HELDER CÂMARA - PDHC
}

\author{
R. F. S. GURGEL e K. B. OLIVEIRA* \\ Instituto Federal de Educação, Ciência e Tecnologia do Rio Grande do Norte \\ kelvin.olveira@ifrn.edu.br*
}

Artigo submetido em julho/2013 e aceito em junho/2015

DOI: $10.15628 /$ holos.2015.1531

\section{RESUMO}

Segundo dados da Organização das Nações Unidas - ONU, a pobreza atualmente assola mais de $1 / 3$ da população mundial. No Brasil esta realidade ganha destaque, sobretudo nas regiões Norte e Nordeste do País e é neste contexto que a Comunidade de Sombras Grandes e Milagres, no município de Caraúbas - RN esta inserida. Até cinco anos atrás as famílias viviam numa situação de pobreza extrema, que foi alterada pela intervenção integrada de ações e políticas públicas, através do Projeto Dom Helder Câmara - PDHC/Secretaria de Desenvolvimento Territorial - SDT/Ministério do Desenvolvimento Agrário - MDA/Fundo Internacional de Desenvolvimento Agrícola - FIDA/ Fundo Global para o Meio Ambiente - GEF - ONU, que dentre tantas atividades passou a substituir o trabalho com a
\end{abstract}

agricultura convencional e a produção de carvão, pela agricultura sustentável com o cultivo de hortas agroecológicas, entre outros. O presente artigo tem como objetivo apresentar uma breve descrição das mudanças ocorridas na renda das famílias a partir da produção, cultivo e comercialização de hortaliças, o que permitiu saltar de uma renda de $\mathrm{R} \$ 90$ reais mensais, pouco mais de $1 / 3$ do salário mínimo em 2005, e chegar a uma renda atual (março 2012) de quase 900 reais ao mês. Caracterizando também os benefícios e a relação das famílias com o meio ambiente a luz desta atividade. Assim, a pesquisa é de natureza qualitativa, pois considera informações socioeconômicas e ambiental, e quantitativa, com base na análise de dados obtidos a partir da aplicação de questionários e entrevistas.

PALAVRAS-CHAVE: pobreza, renda, hortas agroecológicas.

\section{THE IMPACTS IN THE INCOME OF THE FAMILIES OF “SOMBRAS GRANDES" AND “MILAGRES" COMMUNITIES: THE CASE OF DOM HELDER CAMARA PROJECT - PDHC}

\section{ABSTRACT}

According data from United Nations Organization - UN, the poverty now devastates more than $1 / 3$ of the world population. In Brazil this reality wins prominence especially in the North and Northeast areas of the Country and it is in this context that the "Sombras Grandes (Big Shadows, in English)" and "Milagres (Miracles, in English)" Communities are inserted, both in the city of Caraúbas-RN. Up to five years ago the families lived in a situation of extreme poverty, that was altered by the integrated intervention of actions and public politics, through the Project Dom Helder CâmaraPDHC/Territorial Development Secretariat - SDT/ Ministry of Agrarian Development - MDA/ International Fund for Agricultural Development - FIDA/ Global Environment Facility - GEF-UN, that started to substitute the work with the conventional agriculture and the production of coal, for the maintainable agriculture with the cultivation of agronomy-ecological vegetable gardens, among others. The objective of this article is to introduce a brief description of the changes that happened in the income of the families starting from the production, cultivation and commercialization of vegetables that allowed jump from an income of 90 real monthly, little more than $1 / 3$ of the minimum salary in 2005, and reach a current income (march 2012) of almost 900 real per month. Also characterizing as benefits the relationship of the families with the environment based on those changes. Saying this, this research is a qualitative one, because it considers socioeconomic and environmental information, and a quantitative one, based in the analysis of data obtained starting from the application of questionnaires and interviews.

KEYWORDS: petroleum, environmental risks, drilling rig, the risk maps. 


\section{INTRODUÇÃO}

O semiárido brasileiro corresponde a quase $90 \%$ da região nordeste, considerando os estados do Piauí, Ceará, Rio Grande do Norte, Paraíba, Pernambuco, Alagoas, Sergipe e Bahia, e mais a região setentrional do Estado de Minas Gerais, num total de 1133 municípios e uma área de $969.589,4 \mathrm{~km} 2$. São cerca de 21 milhões de pessoas que convivem com as adversidades como a aridez climática, baixa, imprevisível e mal distribuída precipitação pluviométrica e solos empobrecidos de matéria orgânica (SILVA, 2008).

Tendo por base este contexto, o presente artigo apresenta algumas das mudanças ocorridas na Comunidade de Sombras Grandes e Milagres em Caraúbas/RN, no tocante a geração de renda com a produção de hortas agroecológicas em substituição a produção de carvão, a partir da intervenção direta do Projeto Dom Hélder Câmara que tem sua atuação voltada para o semiárido brasileiro e cujas ações estão centradas na pessoa humana e combate a pobreza em assentamentos e comunidades rurais de agricultura familiar, como forma de alterar a realidade local, elaborar referências de convivência e contribuir para o desenvolvimento rural sustentável, tendo por base a agroecologia.

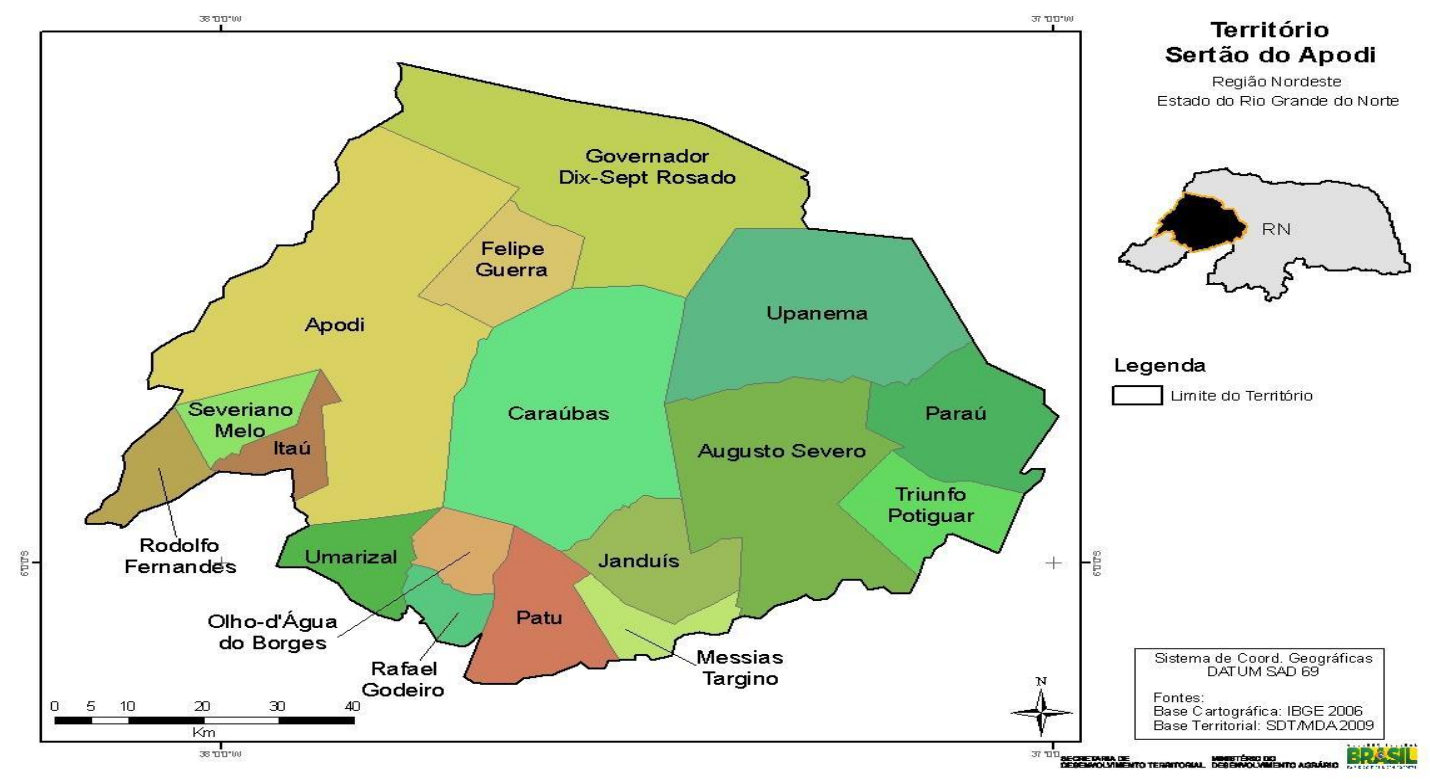

Figura 1 - Mapa do Território da Cidadania Sertão do Apodi/RN

Fonte: Site da Secretaria de Desenvolvimento Territorial - SDT(2009).

O conceito de convivência com a seca ainda é recente e muitas são as formas de desenvolvimento e alternativas propostas para a região, que se caracteriza também pela presença de movimentos sociais atuantes, cujos esforços resultam em várias concepções e formas de desenvolvimento para as famílias que vivem no bioma caatinga e que convivem diariamente com suas características e condições adversas. Assim o trabalho apresentado aqui se assemelha a concepção que considera a convivência com a seca, focada nas pessoas, com manejo sustentável, tecnologias apropriadas e baixo custo, que possibilitem geração de trabalho, renda e qualidade de vida. (SILVA, 2008).

Reconhecendo o papel fundamental da agricultura familiar para a produção de alimentos e o trabalho desenvolvido pelas Organizações não governamentais (ONG's), prestadoras de 
assessoria técnica a longo dos anos, a produção familiar recebeu um novo reforço com a chegada da agroecologia que veio se propagando como um elo de sustentação dos movimentos sociais por seu caráter inovador e por congregar em suas raízes o aumento da produção com ganhos econômicos, mas também como uma preocupação socioambiental. O conceito de agroecologia vem sendo utilizado em muitas situações e com significados também diferentes. No geral evoca uma imagem mais ou menos comum. Onde ao questionar várias pessoas e fazer leituras, a imagem que se destaca é a de uma "agricultura que respeita o meio ambiente", de "práticas agrícolas ecológicas que não destroem a natureza", de "desenvolvimento sustentável". De fato, praticamente todos os autores que escrevem sobre o tema chamam a atenção para o uso diversificado do termo que, se por um lado pode facilitar a difusão de algumas ideias importantes relacionadas à agroecologia, também pode causar algumas confusões e dificuldades quanto à definição de estratégias de promoção do desenvolvimento que têm como base a agroecologia. (BUAINAIN, 2006, p 55).

Assim, mediante tantas definições que se aproximam do trabalho desenvolvido na Comunidade de Sombras Grandes, duas são assumidas como complementares na estratégia do PDHC. A primeira coadunamos com Sidersky et al (2010) que define que a agroecologia fornece os princípios ecológicos básicos para o estudo e manejo de agroecossistemas tanto produtivos quanto conservadores dos recursos naturais, e que sejam culturalmente sensíveis, socialmente justos e economicamente viáveis destacando aqui, além da compreensão da agricultura uma preocupação com os aspectos socioeconômicos e culturais. A segunda baseada em Altieri (2002) onde a agroecologia estabelece como integrante do campo do conhecimento que promovem o manejo ecológico dos recursos naturais através de formas de ação social coletiva que possa apresentar alternativas e propostas de desenvolvimento participativo à atual crise de modernidade. Sendo este um tema atual e de grande repercussão, a proposta aqui apresentada visa mostrar como é possível estimular a agricultura familiar, gerar renda para as famílias e, sobretudo contribuir para o meio ambiente através da educação e ação agroecológica.

\section{METODOLOGIA}

Para chegar a estes dados, foi considerado o trabalho de supervisão e monitoramento realizado desde o ano de 2005, através da Unidade Local de Supervisão do Projeto Dom Helder Câmara que permitiu o acesso a levantamentos, relatórios e informações acerca da área e também às tabelas de acompanhamento semanal da Feira Agroecológica da Agricultura Familiar de Caraúbas/RN, contendo os itens comercializados, a quantidade e o valor arrecadado. Através da realização de entrevistas com o Presidente da Associação da Comunidade e com o Assessor Técnico que acompanha a área foi possível mapear as outras fontes de comércio dos produtos e ter acesso aos valores e a quantidade mensal fornecida, e por último com a realização de visitas no local e a aplicação de um questionário contendo questões objetivas e subjetivas junto às oito famílias envolvidas com a atividade das hortas, os reflexos advindos a partir do aumento na renda puderam ser mensurados, assim como os bens adquiridos a partir de então. 


\section{CONTEXTUALIZAÇÃO DA COMUNIDADE}

A associação Comunitária de Sombras Grandes e Milagres, localizada a $30 \mathrm{~km}$ da sede do Município de Caraúbas surgiu a partir da junção dos moradores da comunidade Sombras Grandes com os da Comunidade Milagres. As famílias são originárias do município de Caraúbas e de cidades vizinhas e as terras vêm sendo passadas de pai para filho ao longo dos anos através da partilha de herança. Nem todas as famílias são proprietárias, algumas construíram suas casas na terra dos pais ou parentes. São cerca de 30 famílias que até pouco tempo se assemelhavam a realidade dos muitos povoados da região semiárida do Nordeste Brasileiro, desprovidas das principais necessidades básicas como saúde, educação, moradia, abastecimento de água, energia elétrica e, sobretudo pela carência de oportunidades de emprego e geração de renda para estas famílias do campo. Como agricultores tradicionais a maioria das famílias tinha seus roçados de sequeiro, onde plantavam culturas como milho feijão e algodão e também criavam pequenos animais, onde em anos de bom inverno a venda destes gerava uma pequena renda que não era suficiente para assegurar a sobrevivência. Assim muitos eram obrigados a deixar suas casas e trabalhar na "diária" ou no desmatamento da mata para vender o carvão.

Num levantamento realizado no ano de 2005 a renda familiar girava em torno de 90 reais/mês, o que representava pouco mais que $1 / 3$ do salário mínimo vigente que era de 260,00 reais. (PDHC/ULS 2005). Sem muitas alternativas de produção, nem reservatórios de água as pessoas da Comunidade percorriam cerca de $6 \mathrm{~km}$ de distancia em jumento, cavalo ou carroça para matar a sede, já que os dois poços perfurados na comunidade não funcionavam. Associado a isso outro grande problema enfrentado era a ausência de assessoramento técnico, que só existiu em alguns momentos de forma pontual e descontinuada, deixando desamparados os agricultores e agricultoras tanto nas questões organizativas, quanto na busca por alternativas de produção e enfrentamento da pobreza.

\section{A INTERVENÇÃO DO PROJETO DOM HELDER CÂMARA - PDHC}

O Projeto Dom Hélder Câmara - PDHC é fruto de um acordo de empréstimo Internacional, entre o MDA (Ministério do Desenvolvimento Agrário) e o FIDA (Fundo Internacional de Desenvolvimento Agrícola) das nações unidas, que acontece no Semiárido do Nordeste do Brasil, com o objetivo de produzir e difundir referências que contribuam para o fortalecimento local, participativo e solidário e orientem ações de políticas públicas que possam combater a pobreza, promovendo assim o desenvolvimento rural sustentável (SIDERSKY et al 2010). O projeto atua em seis Estados (Rio Grande do Norte, Paraíba, Piauí, Ceará, Sergipe e Pernambuco), estando presente em oito territórios ${ }^{1}$. No Rio Grande do Norte a atuação do PDHC esta localizada no Território da cidadania Sertão do Apodi (figura 1), que é composto por dezessete municípios, atuando em 10 destes (figura 2): Apodi, Caraúbas, Governador Dix Sept Rosado, Upanema, Umarizal, Rafael

\footnotetext{
${ }^{1}$ Espaço físico, geograficamente definido, geralmente continuo, compreendendo cidades e campos caracterizados por critérios multidimensionais, tais como o ambiente, a economia, a sociedade, a cultura, a política e as instituições, e uma população com grupos sociais relativamente distintos, que se relacionam interna e externamente por meio de processos específicos, onde se pode distinguir um ou mais elementos que indicam identidade e coesão social, cultural e territorial (MDA, 2005, p.11).
}

HOLOS, Ano 31, Vol. 6 
Godeiro, Olho D'água do Borges, Felipe Guerra, Campo Grande e Janduís, dos dezessete que compõem este território, tendo no município de Apodi a Unidade Local de Supervisão.

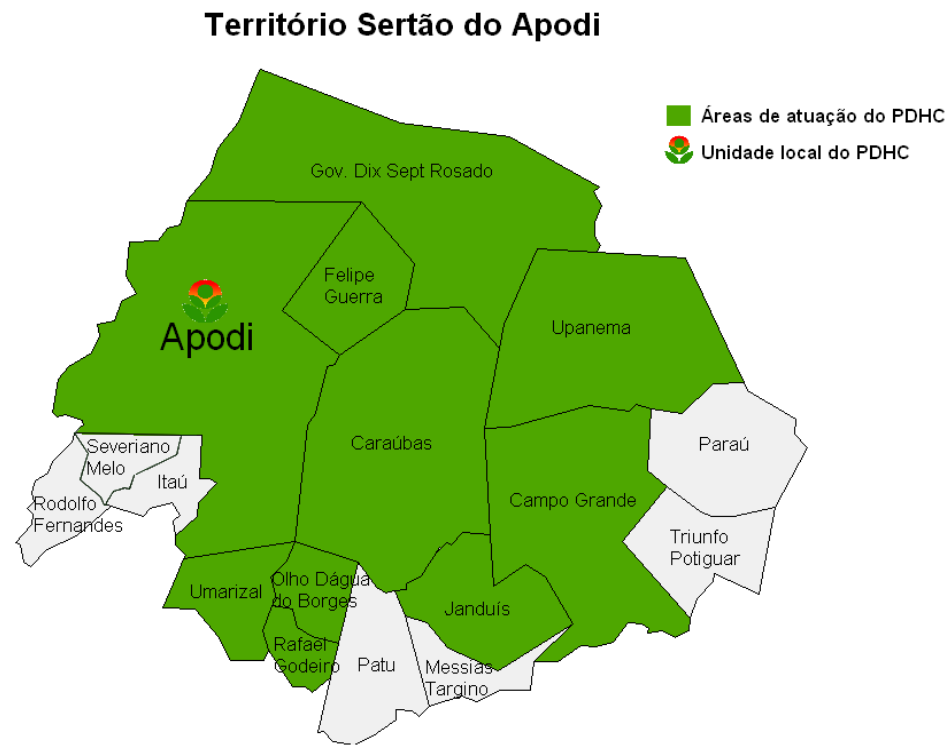

Figura 2 - Mapa dos municípios de atuação do PDHC no Território Sertão do Apodi/RN Fonte: Unidade Local de Supervisão - ULS/PDHC.

A atuação direta esta focada em 60 áreas de Assentamentos de Reforma Agrária e Comunidades Rurais de Agricultura Familiar, atendendo aproximadamente 2.466 famílias. (PDHC/ULS 2012). A grande essência do Projeto está em "desenvolver uma proposta de Assessoria Técnica, diferenciada e multidisciplinar concebida como uma ação contínua, sistêmica, pautada pelas demandas, interesses e necessidades das famílias beneficiárias e referendada também em posicionamento técnico que se baseia nos princípios da agroecologia" (PDHC, 2008).

A assessoria técnica é executada por Organizações não Governamentais ONG's composta por técnicos capacitados para atender as demandas locais e realizar junto com as famílias as ações constantes dos contratos anuais firmados. Para elaboração dos planos de trabalhos, a cada ano é realizado o planejamento de cada Comunidade/Assentamento onde as ações são definidas e priorizadas pelas próprias famílias, cabendo às prestadoras de serviços de ATP - Assessoria Técnica Permanente, acompanhar o processo e colocar o resultado das oficinas locais no papel, que só passam a constar dos contratos mediante aprovação final do comitê territorial ${ }^{2}$ do PDHC. No ano de 2005, numa ampliação do número de famílias a comunidade passou a integrar o plano de ação da ONG Atos - Assessoria, Consultoria e Capacitação Técnica Orientada Sustentável e a receber a intervenção direta das ações do PDHC. O primeiro passo foi à criação da associação comunitária, composta por trinta famílias juntando Sombras Grandes e Milagres, pela proximidade das propriedades e pela afinidade constituída ao longo dos anos. O segundo passo veio logo em seguida com a discussão de como interferir na realidade local, agravada pelas adversidades climáticas e pela ausência de políticas públicas para o enfrentamento da pobreza, com a perspectiva de desenvolvimento sustentável, sintetizado com propriedade no relatório das NAÇÕES UNIDAS, Nosso Futuro Comum, 1991, como o:

2 É formado por 154 membros, onde 16,23\% são representantes de órgãos governamentais e 83,77\% são da sociedade civil, onde destes 46,5 \% são beneficiários diretos.(ULS/PDHC - Apodi/RN 2010). 
"processo capaz de satisfazer as necessidades das gerações presentes sem comprometer a capacidade das gerações futuras satisfazerem as suas próprias necessidades", ou como "um processo de mudança na qual a exploração dos recursos, a orientação dos investimentos, os rumos do desenvolvimento tecnológico e a mudança institucional estão de acordo com as necessidades atuais e futuras".

O mesmo relatório também faz uma abordagem quando diz que:

“a pobreza não é apenas um mal em si mesma, mas para haver um desenvolvimento sustentável é preciso atender as necessidades básicas de todos e dar a todos a oportunidade de realizar suas aspirações de uma vida melhor. Um mundo onde a pobreza é endêmica estará sempre sujeito a catástrofes ecológicas ou de outra natureza."

Tendo por base estes conceitos que vão de acordo à frase que norteia a ação do PDHC, "investindo no ser humano, transformando o semiárido", iniciou-se um arranjo institucional com a busca de parceiros e as discussões para elaboração de um projeto técnico que pudesse atender as necessidades da comunidade e, sobretudo ter uma visão educativa com o meio ambiente.

\section{A CHEGADA DA AGROECOLOGIA}

A partir das reuniões com a Comunidade, foi discutida uma proposta para atender as necessidades imediatas, onde se elaborou um grande projeto integrado, tendo como financiadores principais a Petrobras, com as ações do Projeto "Molhar a Terra", do Programa Petrobras Fome Zero e o PDHC, que teve por finalidade implantar um projeto produtivo integrado com a produção de hortas e fruteiras irrigadas e toda a estrutura necessária, como também o apoio à produção de mel, avicultura, caprinocultura e o plantio de culturas de sequeiro para suporte forrageiro e subsistência. A partir da organização instituída outros parceiros participaram ativamente das muitas mudanças que estavam por vir: o Programa Luz Para Todos trouxe a energia para as casas, a Prefeitura Municipal realizou a substituição das casas de taipa por alvenaria e em paralelo o PDS - Programa de Desenvolvimento Solidário do Governo do Estado do RN, cofinanciado pelo Banco Mundial financiou o sistema que passou a levar a água do poço (reativado pela Petrobras) encanada para as casas das famílias, melhorando consideravelmente as condições básicas e sanitárias. Com a recuperação de dois poços ${ }^{3}$ pela Petrobras além de levar água de qualidade para as residências, também foi possível alimentar um sistema de irrigação numa área de aproximadamente um hectare destinada ao cultivo de hortas, pomares e capineira. No ano de 2009 foi instalada uma segunda área de 3,0 hectares, onde destes 0,8 também foi destinado para a produção de hortas, assim foi preciso perfurar um novo poço para atender esta demanda também financiada pelos recursos da Petrobras.

O novo poço apresenta uma vazão de $12.000 \mathrm{l} / \mathrm{h}$ (ATOS 2012). Junto com a implantação das etapas do projeto, também se iniciou um assessoramento técnico e capacitação para a conversão dos seus sistemas tradicionais de cultivo pela estratégia agroecológica. Considerando que até

${ }^{3}$ O nível dinâmico dos poços varia entre 45 e 60 metros de profundidade com vazão de aproximadamente 4.000 litros/hora, com qualidades distintas onde um apresenta classificação C1S1 e o outro C3S1. (Sidersky et. al. 2010). 
pouco tempo, a agroecologia era praticamente desconhecida na Comunidade, pode-se dizer que esta nova forma de produzir foi bem recebida pela maioria dos agricultores e agricultoras, que embora tivessem suas dúvidas com relação ao sucesso desta tecnologia, alimentadas pela limitação de conhecer apenas a produção convencional, que vinha sendo desenvolvida ao longo dos anos, demostraram estar abertos a este novo aprendizado.

Para dar seguimento as atividades foi necessário também garantir um trabalho permanente de assessoria técnica as famílias, para que os benefícios trazidos com a produção agroecológica fossem percebidos não apenas através dos resultados alcançados com a produção, mas também influenciassem diretamente na forma de perceber a natureza e respeitar o meio ambiente, para de fato ser apropriado não apenas pelas famílias que aderiram ao projeto, mas para toda a Comunidade e entorno, assegurando o repasse e continuidade para as gerações futuras. No trabalho com as hortaliças são oito famílias diretamente envolvidas, que realizam suas atividades de forma individual, onde cada família é responsável pelos seus canteiros na área coletiva.

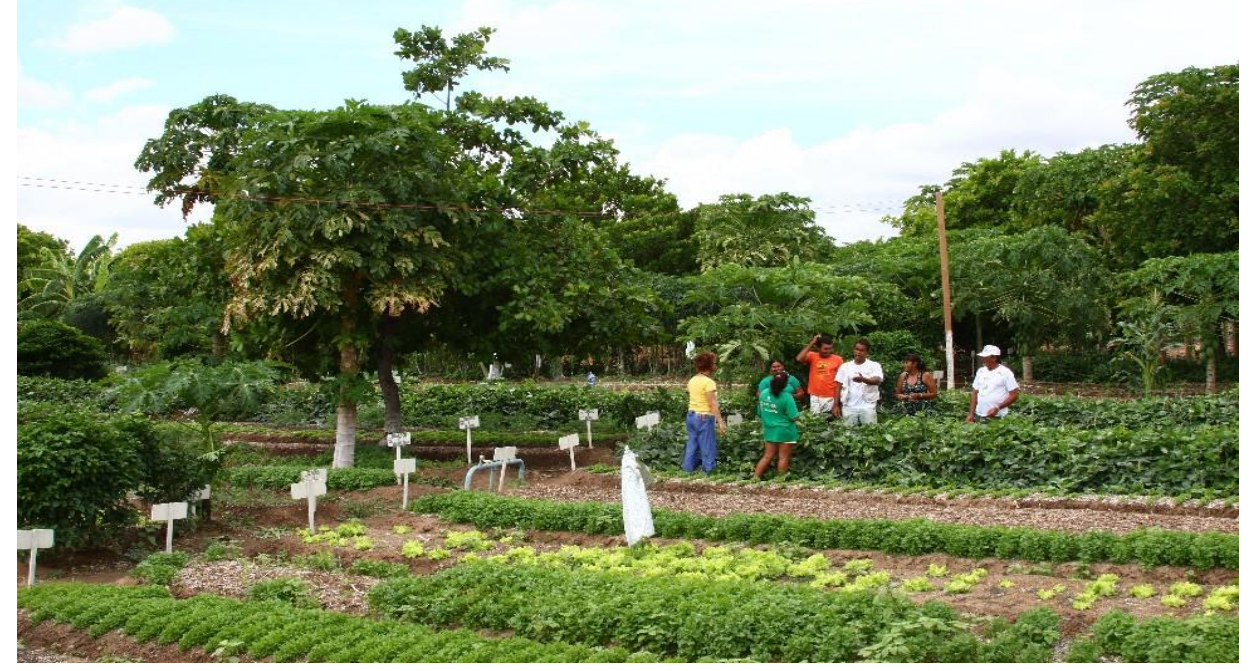

Figura 4 - Hortas de Sombras Grandes e Milagres - Caraúbas/RN. Fonte: ULS/PDHC - Apodi(2007).

O planejamento da produção e a comercialização dos produtos é feito em conjunto, bem como a escala de trabalho para irrigação da área que obedece a um sistema de rodízio entre os agricultores e agricultoras. Cada família possui em média 10 canteiros, com cerca de um metro de largura e trinta metros de comprimento, onde é feito o plantio das hortaliças que é bastante diversificado com culturas como: alface, tomate cereja, rúcula, coentro, cebolinha, beterraba, couve, berinjela, repolho, nabo, pimentão, cenoura, hortelã, macaxeira e etc. Para o cultivo das hortas além da diversificação existe o cuidado com o manejo do solo, onde as famílias fazem a rotação de culturas, adubação verde, compostagem e ainda cultivam plantas repelentes e isca para reduzirem a possibilidade de ataques por pragas ou doenças, de acordo com os princípios agroecológicos. Uma curiosidade é que observando os canteiros na área coletiva estes são identificados pelo nome do homem e da mulher, registrando assim um crescimento nas relações sociais e na busca pela equidade de gênero.

O trabalho com hortaliças agroecológicas é o cartão de visitas desta comunidade que dispõe também de um viveiro de mudas, minhocário e de uma "unidade" para lavagem, separação 
e embalagem dos produtos a serem comercializados. Paralelo ao cuidado com a produção também acontece a busca por estratégias que possam dialogar com a legislação brasileira dos orgânicos através da certificação, assim recentemente 4 dos 8 produtores da Comunidade e também a Associação dos Produtores da Feira Agroecológica da Agricultura Familiar de Caraúbas receberam a declaração de cadastro como Organismo de Controle Social - OCS emitido pela Superintendência Federal de Agricultura no Rio Grande do Norte ( SFA - RN), do Ministério da Agricultura, Pecuária e Abastecimento - MAPA. Com este certificado de produtor orgânico, os agricultores familiares já estão habilitados a vender diretamente ao consumidor e a programas governamentais de aquisição de alimentos. Agora o próximo passo para consolidar a certificação orgânica é a criação de um Organismo Participativo de Avaliação de Conformidade - OPAC que é uma opção de certificação permitida pela legislação brasileira para os agricultores e agricultoras familiares organizados através de Sistemas Participativos de Garantia, para gerar o selo orgânico.

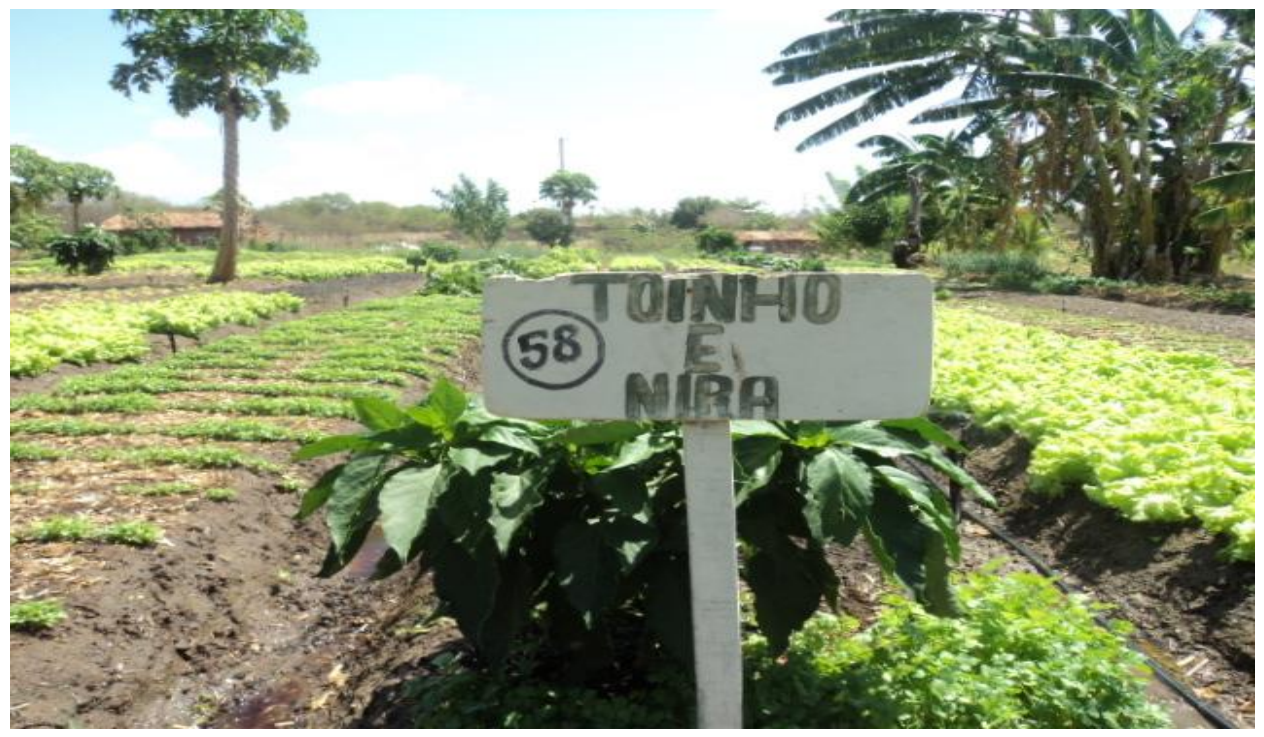

Figura 5 - Hortas de Sombras Grandes e Milagres - Caraúbas/RN.

Fonte: Autor (2012).

\section{AS MUDANÇAS E RESULTADOS NA RENDA DAS FAMÍLIAS}

Dentro do projeto elaborado junto a Petrobras foi possível adquirir um transporte que é utilizado, sobretudo para a comercialização dos produtos, que é realizada da seguinte forma: grande parte da venda é realizada na Feira Agroecológica da Agricultura Familiar de Caraúbas/RN que acontece aos sábados, onde a cada semana duas famílias se reversam para vender a produção do grupo em uma das 10 barracas que compõem a feira. Para isso o grupo de oito famílias realiza a colheita na sexta feira, preparam os produtos identificando a quantidade enviada por cada um, o que simplifica a prestação de contas que se torna rápida e fácil, pois depois de retiradas as despesas, cada um recebe proporcional àquilo que enviou para a feira.

Fazendo o somatório da renda das feiras do mês de março de 2012, temos uma renda mensal de $R \$ 2.566,30$ reais para os oitos agricultores que trabalham com hortaliças, com a venda na feira da agricultura familiar. Outra parte dos produtos é comercializada através da venda direta ao consumidor com a entrega de 50 cestas semanais ao preço médio de $\mathrm{R} \$ 15$ reais, para 
consumidores do município de Mossoró/RN, contendo cerca de 10 produtos, onde no mês de março de 2012 o valor alcançado foi de R\$ 3000 reais, conforme informações prestadas pela diretoria da Associação. Um comércio local também esta comprando semanalmente cerca de 400 pés de alface ao preço de $R \$ 0,65$ centavos a unidade, totalizando uma venda mensal de 1600 pés, o que equivale a $\mathrm{R} \$ 1.040,00$ reais. Em menor escala também são realizadas vendas diretas no local, aonde comunidades vizinhas vem comprar produtos direto na horta. Esta venda, segundo relatórios de monitoramento da ONG Atos, deixa uma renda de $\mathrm{R} \$ 200$ reais por mês aproximadamente. Também mensalmente são vendidos para a Comunidade de Mirandas cerca de $\mathrm{R} \$ 255,00$ reais, fruto da venda de alface, coentro, tomate e cebolinha. Outros canais de comercialização já estão sendo negociados, onde a partir do mês de setembro de 2012 estima-se uma venda de 200 unidades de alface e $20 \mathrm{~kg}$ de tomates para uma churrascaria do município sendo esta uma demanda semanal (ATOS 2012).

A partir do acompanhamento realizado, dos questionários aplicados e das informações fornecidas pela ULS/PDHC e pela ATOS, ao somarmos as vendas das diferentes fontes de comércio, tomando por referência o mês de março de 2012, temos um renda total mensal de $\mathrm{R} \$ \mathbf{7 . 0 6 1 , 3 0} 0$ gráfico abaixo mostra o desempenho e o destino das vendas do grupo de hortaliças durante o mês de março de 2012:

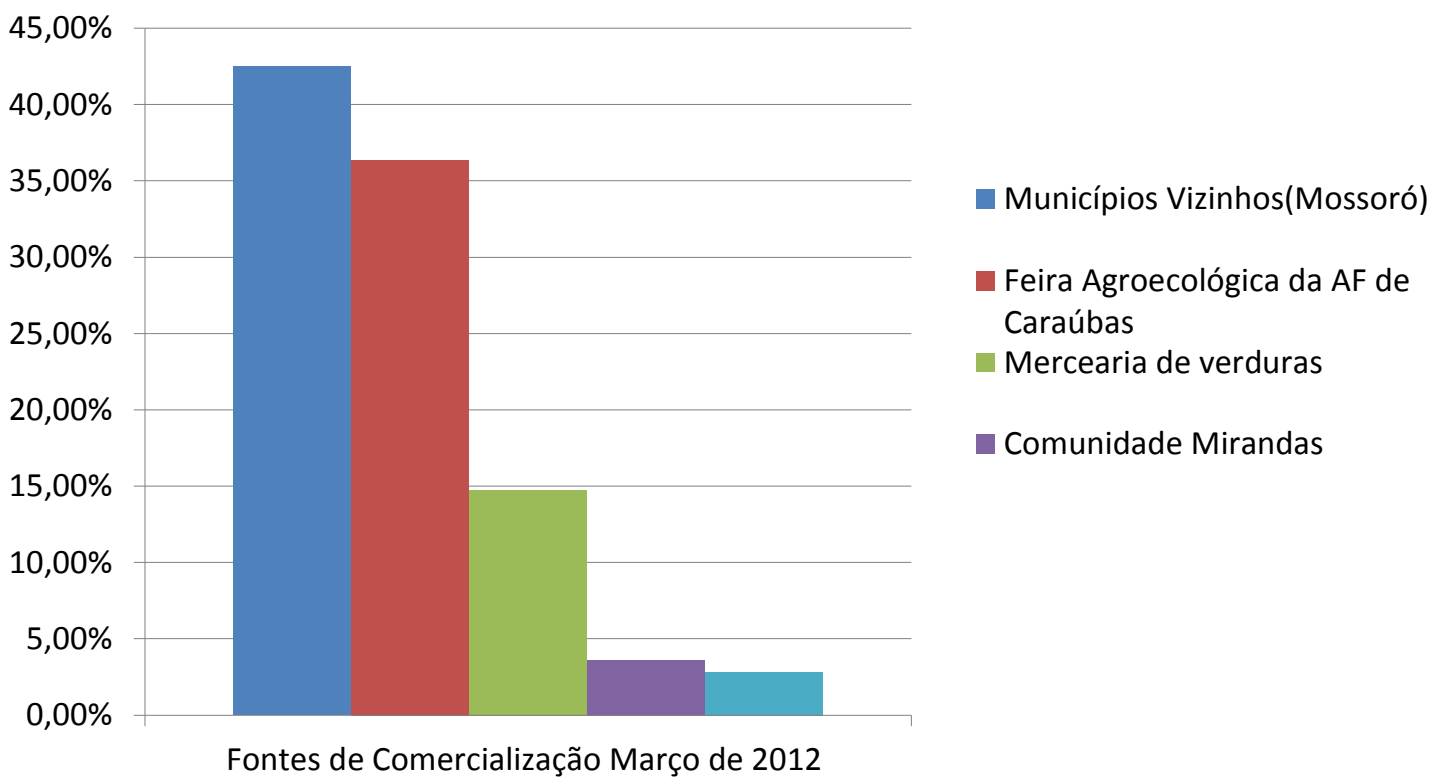

Figura 5 - Gráfico de desempenho das Vendas. Fonte: Autor (2012).

Deste valor aproximadamente $R \$ 240,00$ reais são retirados para cobrir as despesas com sementes, veículo e energia elétrica, resultando o valor de $\mathrm{R} \$ 6.821 .30$ para ser dividido entre o grupo de oito participantes. Considerando que a demanda de produtos oferecida por cada família é muito semelhante e que as despesas são divididas igualmente, chegamos a uma renda mensal de $R \$ 852,66$ para cada uma das oito famílias que compõem o grupo das hortas. Observando que a renda familiar vem sendo complementada a partir da produção de hortaliças desde 2005, em questionário aplicado com as oito famílias, verificamos que este incremento contribuiu para a aquisição de alguns bens, conforme tabela abaixo: 
Tabela 1 - Bens adquiridos.

\begin{tabular}{|c|c|}
\hline \multicolumn{2}{|c|}{ Bens adquiridos a partir de 2005: } \\
\hline Ítem Comprado & Quantidade de famílias que adquiriram: \\
\hline Geladeira & 8 \\
\hline Televisão & 8 \\
\hline Antena Parabólica & 8 \\
\hline Máquina de lavar roupas & 3 \\
\hline Fogão & 1 \\
\hline Celular & 8 \\
\hline Ventilador & 7 \\
\hline DVD & 1 \\
\hline Liquidificador & 7 \\
\hline Bicicleta & 7 \\
\hline Moto & 2 \\
\hline
\end{tabular}

É importante considerar que tudo aquilo que não se precisa comprar reflete positivamente na renda mensal familiar, assim os resultados também nos mostram que em média, $R \$ 22,50$ reais por semana, deixaram de serem gastos com o consumo de legumes e verduras (este valor não foi considerado para o cálculo apresentado) e que hoje as famílias tem uma alimentação mais saudável colhendo seus produtos diretamente do quintal, o que vem mudando drasticamente os hábitos alimentares e deixando colorido o prato que antes era "preto e branco", conforme fala das próprias famílias.

\section{CONSIDERAÇÕES FINAIS}

A Comunidade de Sombras Grandes e Milagres passou por muitas transformações a partir do ano de 2005, com a intervenção direta da ação governamental do Projeto Dom Helder Câmara e parceiros, que mudaram não apenas as condições de vida das famílias, mas também o jeito de pensar o ambiente e conviver com este. Outro fator relevante é que as mesmas oito famílias do grupo de hortas que atualmente conseguem obter uma renda mensal de mais de um salário mínimo com a comercialização da produção agroecológica, fazem parte do conjunto da Comunidade que há menos de 7 anos buscava a sobrevivência através do desmatamento da mata e da fabricação do carvão para obter uma renda de aproximadamente $\mathrm{R} \$ 90$ reais mensais, 34,61\% do salário mínimo da época (PDHC, 2005) e atualmente recebem 137,08\% do salário vigente que é de $\mathrm{R} \$ 622,00$ reais. Desse modo, fica claro a percepção de como um projeto bem articulado pode mudar o modo de pensar e agir sobre o meio, a partir de práticas de educação ambiental, onde é possível gerar renda para as famílias do campo de forma equilibrada e sustentável.

É importante registrar que os dados aqui apresentados tratam especificamente da produção de hortaliças, muito embora as mesmas oito famílias também tenham boas vendas com a produção de fruteiras cultivadas nos mesmos padrões de sustentabilidade e também participem de outros projetos produtivos como apicultura, caprinocultura, avicultura e etc advindos da mesma intervenção que vão de encontro às potencialidades e o saber de cada um. Estes também ainda mantem seus roçados e cultivos de sequeiro e continuam criando seus animais, com orientação técnica apropriada e baseada na agroecologia. Também é oportuno citar que os agricultores mencionaram algumas dificuldades surgidas ao longo do caminho, por se tratar, 
sobretudo de um projeto que respeita a aptidão local e é formado por grupos distintos, porém os resultados impulsionam o esforço em continuar aprendendo e seguindo em frente.

Devido a essas peculiaridades, ainda cabe espaço para registrar que além de comercializar seus produtos, as famílias também passaram a consumir alimentos saudáveis melhorando significativamente a saúde e a qualidade de vida da Comunidade como um todo e que com esta complementação na renda, bens que antes eram apenas objetos da imaginação, estão presentes nas residências como é o caso da geladeira e da televisão, que foram os primeiros itens comprados na linha de necessidade dos agricultores e agricultoras familiares. Outro fato relevante é que os resultados obtidos nesta área tem também a pretensão de disseminar conhecimentos para outras comunidades e assentamentos, assim muitos intercâmbios, visitas, documentários, relatórios, e etc. vêm sendo divulgados para tornar público este processo de transformação da realidade local e também o caráter de experimentação e aprendizado desencadeado a partir desta ação, que serve como referência para toda a região semiárida do Nordeste do Brasil e que já circula em nível mundial.

\section{REFERÊNCIAS}

1. ALTIERI, M. A. Agroecologia: bases científicas para uma agricultura sustentável. Guaíba, RS: Agropecuária. 2002. 592 páginas.

2. Assessoria, Consultoria e Capacitação Técnica Orientada Sustentável - ATOS. Caraúbas/RN.

3. BUAINAIN, A. M. Agricultura Familiar, agroecologia e desenvolvimento sustentável: questões para debate. Antonio Márcio Buainain; colaboração de Hildo Meireles de Souza Filho. Brasília. - Brasília: IICA, 2006. 136 páginas.

4. NAÇÕES UNIDAS. Nosso Futuro Comum. Nova lorque. EUA, 2aㅡ ED. - 1991, 166 páginas.

5. Organização das Nações Unidas - ONU. www.onu.org.br

6. Portal Brasil - Índices Financeiros Brasileiros. www.portalbrasil.net/salariominimo

7. Projeto Dom Helder Câmara - PDHC/SDT/MDA/FIDA - ONU, Unidade Local de Supervisão no RN e Unidade Gerencial do Projeto - UGP em Recife/PE. www.projetodomhelder.gov.br.

8. REFERÊNCIAS PARA UMA ESTRATÉGIA DE DESENVOLVIMENTO RURAL NO BRASIL. In: Série Documentos Institucionais № 01 - SDT. Brasília: Ministério do Desenvolvimento Agrário; Março de 2005.

9. Sevilla Guzmán, E.(2006).De la sociología rural e la agroecología. Andalúcia, Junta de Andalucía / Consejería de Agricultura y Pesca / Icaria.

10. SIDERSKY, P.; JALFIM, F.T.; ARAÚJO, E.R. A estratégia de assessoria técnica do Projeto Dom Helder Camara - 2a ED. - Recife, PE: PDHC, 2010, 166 páginas

11. SILVA, Roberto Marinho Alves da. Entre o combate à seca e a convivência com o semiárido transições paradigmáticas e sustentabilidade do desenvolvimento. Série BNB Teses e Dissertações Fortaleza, CE, BNB, 2008. 